\title{
Underuse of prehospital strategies to reduce time to reperfusion for ST-elevation myocardial infarction patients in 5 Canadian provinces
}

\author{
Michael J. Schull, MD; ${ }^{*}+$ Samuel Vaillancourt, MD; ${ }^{\dagger}$ Linda Donovan, MBA; ${ }^{*}$ Lucy J. Boothroyd, PhD; ${ }^{\S}$ \\ Dug Andrusiek, MSc; ${ }^{\ddagger}$ John Trickett, BScN; ${ }^{* *}$ Sunil Sookram, MD; ${ }^{\dagger \dagger}$ AndrewTravers, MD; $;{ }^{\neq \ddagger}$ Marian J. \\ Vermeulen, MHSc; ${ }^{*}$ Jack V.Tu, MD; ${ }^{*} \ddagger \S \S$ for the Canadian Cardiovascular Outcomes Research Team
}

See related articles on pages 423 and 481

\section{ABSTRACT}

Objective: Timely reperfusion therapy for ST-elevation myocardial infarction (STEMI) is an important determinant of outcome, yet targets for time to treatment are frequently unmet in North America. Prehospital strategies can reduce time to reperfusion. We sought to determine the extent to which emergency medical services (EMS) use these strategies in Canada.

Methods: We carried out a cross-sectional survey in 2007 of ground EMS operators in British Columbia, Alberta, Ontario, Quebec and Nova Scotia. We focused on the use of 4 prehospital strategies: 1) 12-lead electrocardiogram (ECG), 2) routine expedited emergency department (ED) transfer of STEMI patients (from a referring ED to a percutaneous coronary intervention $[\mathrm{PCl}]$ centre), 3) prehospital bypass (ambulance bypass of local EDs to transport patients directly to $\mathrm{PCl}$ centres) and 4) prehospital fibrinolysis.

Results: Ninety-seven ambulance operators were surveyed, representing 15681 paramedics serving $97 \%$ of the combined provincial populations. Of the operators surveyed, $68 \%(95 \%$ confidence interval $[\mathrm{Cl}] 59 \%-77 \%$ ) had ambulances equipped with 12-lead ECGs, ranging from $40 \%$ in Quebec to $100 \%$ in Alberta and Nova Scotia. Overall, $47 \%$ (95\% Cl 46\%-48\%) of paramedics were trained in ECG acquisition and $40 \%(95 \% \mathrm{Cl}$ $39 \%-41 \%)$ were trained in ECG interpretation. Only 18\% (95\% $\mathrm{Cl} 10 \%-25 \%)$ of operators had prehospital bypass protocols; $45 \%$ (95\% Cl 35\%-55\%) had protocols for expedited ED transfer. Prehospital fibrinolysis was available only in Alberta. All EMS operators in British Columbia, Alberta and Nova Scotia used at least 1 of the 4 prehospital strategies, and one-third of operators in Ontario and Quebec used 0 of 4 . In major urban centres, at least 1 of the 3 prehospital strategies 12-lead ECG acquisition, bypass or expedited transfer was used, but there was considerable variation within and across provinces.

Conclusion: The implementation of widely recommended prehospital STEMI strategies varies substantially across the 5 provinces studied, and relatively simple existing technologies, such as prehospital ECGs, are underused in many regions. Substantial improvements in prehospital services and better integration with hospital-based care will be necessary in many regions of Canada if optimal times to reperfusion, and associated outcomes, are to be achieved.

Keywords: acute myocardial infarction, reperfusion, prehospital care, paramedics, emergency medicine

\section{RÉSUMÉ}

Objectif : L'administration précoce d'un traitement de reperfusion en cas d'infarctus du myocarde avec sus-décalage du segment ST (STEMI) est un déterminant important du devenir du patient. Or, en Amérique du Nord, les points de repère établis quant au temps écoulé jusqu'au traitement sont, dans une large mesure, non respectés. Pourtant, des stratégies préhospitalières peuvent réduire le délai de reperfusion. Nous avons cherché à déterminer dans quelle mesure les services médicaux d'urgence (SMU) utilisent ces stratégies au Canada. Méthode : Nous avons mené, en 2007, une enquête transversale auprès des SMU terrestres en Colombie-Britannique, en Alberta, en Ontario, au Québec et en Nouvelle-Écosse. Nous avons concentré notre enquête sur I'utilisation de 4 stratégies préhospitalières : 1) électrocardiogramme (ECG) à 12 dérivations; 2) transfert routinier accéléré des services d'urgence

From the *Institute for Clinical Evaluative Sciences, Toronto, Ont., the Division of Emergency Medicine, Department of Medicine, University of Toronto, Toronto, Ont., ¥Sunnybrook Health Sciences Centre, Toronto, Ont., §Agence d'évaluation des technologies et des modes d'intervention en santé, Montréal, Que., \Emergency and Health Services Commission, Vancouver, BC, **Base Hospital Program, Ottawa Hospital, Ottawa, Ont., †tthe Department of Emergency Medicine, University of Alberta, Calgary, Alta., and ¥\#Emergency Health Services, Halifax, NS, $\S \S$ Department of Medicine, University of Toronto, Toronto, Ont.

Submitted Jul. 7, 2008; Revised Nov. 14, 2008; Accepted Dec. 9, 2008

This article has been peer reviewed.

CJEM 2009;11(5):473-80 
pour les patients victimes d'un STEMI (d'un service d'urgence $d^{\prime}$ 'origine à un centre d'interventions coronariennes percutanées [ICP]); 3) réorientation préhospitalière (redirection de I'ambulance des services d'urgences locaux vers un centre $d^{\prime}(C P)$; et 4) fibrinolyse préhospitalière.

Résultats : Nous avons interrogé 97 SMU, soit 15681 ambulanciers desservant $97 \%$ de l'ensemble des populations des provinces. Parmi les SMU interrogés, 68 \% (intervalle de confiance [IC] à $95 \%$ de 59 à $77 \%$ ) avait des ambulances équipées d'ECG à 12 dérivations, de $40 \%$ au Québec à $100 \%$ en Alberta et en Nouvelle-Écosse. Dans I'ensemble, $47 \%$ (IC à $95 \%$ de 46 à $48 \%$ ) du personnel ambulancier avaient été formé à l'acquisition d'ECG et $40 \%$ (IC à $95 \%$ de 39 à $41 \%$ ) avaient reçu une formation sur l'interprétation de I'ECG. Seuls $18 \%$ (IC à $95 \%$ de 10 à $25 \%$ ) des SMU avaient des protocoles de réorientation préhospitalière; $45 \%$ (IC à $95 \%$ de 35 à $55 \%$ ) avaient des protocoles pour le transfert accéléré de l'urgence. La fibrinolyse préhospitalière n'était disponible qu'en Alberta. Tous les SMU en Colombie-Britannique, en Alberta et en Nouvelle-Écosse ont utilisé au moins 1 des 4 stratégies préhospitalières, et un tiers des SMU en Ontario et au Québec n'ont utilisé aucune des 4 stratégies. Dans les grands centres urbains, au moins 1 stratégie (acquisition d'ECG à 12 dérivations, réorientation ou transfert accéléré) a été utilisée, mais nous avons noté des écarts considérables entre les provinces et à l'intérieur de celles-ci.

Conclusion : La mise en œuvre de stratégies préhospitalières largement recommandées relatives au STEMI varie considérablement dans les 5 provinces étudiées, et des techniques relativement simples, telles que I'ECG préhospitalier, sont sous-utilisées dans de nombreuses régions. Il faudra améliorer considérablement les services préhospitaliers et mieux les intégrer aux soins hospitaliers dans de nombreuses régions du Canada si l'on veut atteindre un délai de reperfusion optimal et améliorer le devenir des patients.

\section{INTRODUCTION}

Early reperfusion therapy for ST-elevation myocardial infarction (STEMI) has been shown to reduce mortality. ${ }^{1}$ Time to treatment remains one of the most important predictors of STEMI outcome, regardless of whether reperfusion is achieved with percutaneous coronary intervention (PCI) or fibrinolysis..$^{2-6}$ Current American Heart Association/American College of Cardiology (AHA/ACC) clinical practice guidelines suggest that fibrinolytic therapy should be given within $30 \mathrm{~min}-$ utes (or PCI within $90 \mathrm{~min}$ ) of first medical contact, such as arrival at an emergency department (ED) or first patient interaction with paramedics following a 911 call. ${ }^{7}$ Yet there is strong evidence that these targets remain frequently unmet in Europe and North America, and that only modest progress has been made to improve time to reperfusion. ${ }^{1,8-14}$

The AHA/ACC guidelines stress the importance of the role of emergency medical services (EMS) in the implementation of prehospital strategies, and encourage the development of a systems approach to reduce reperfusion delays. ${ }^{7}$ Prehospital 12-lead electrocardiography (ECG) with advance hospital notification for patients with suspected STEMI has been associated with reduced time to reperfusion in several studies, ${ }^{15-18}$ and is recommended as an effective approach to minimize delays. ${ }^{7}$ Other recommended strategies to meet reperfusion target times are expedited transfer of STEMI patients from hospitals without PCI capabilities to hospitals with PCI capabilities, and bypassing a non-PCI hospital for a PCI hospital when EMS personnel suspect STEMI. ${ }^{1,719-24}$
Finally, a number of clinical trials, including several from Canada, have demonstrated the feasibility and safety of prehospital administration of fibrinolytics to patients with STEMI ${ }^{11,25-32}$ and this is recommended as an alternative strategy for EMS systems capable of fibrinolytic therapy to minimize total ischemic time., ${ }^{8,19}$

The degree to which EMS operators have adopted recommended strategies to detect and facilitate treatment of STEMI patients is unclear, despite growing evidence that the strategies are effective in reducing reperfusion delays. ${ }^{4,33}$ Current data from the United States shows that fewer than $10 \%$ of STEMI patients transported by EMS have a prehospital 12-lead ECG recorded..$^{34,35}$ We sought to determine the extent to which Canadian EMS operators have implemented these prehospital strategies for patients with suspected STEMI.

\section{METHODS}

We conducted a survey of EMS operators in the provinces of British Columbia, Alberta, Ontario, Quebec and Nova Scotia between February and August 2007. Emergency medical services in British Columbia and Nova Scotia are organized and administered by a single provincial operator. In Ontario and Alberta they are organized and administered by operators aligned with municipalities. In Quebec operators aligned with health regions carry out these tasks. Ambulance operators were identified by provincial collaborators with administrative positions in EMS. Because of the large number of independent land EMS operators in Alberta $(n=108)$, most of which are small and rural, a list of 
17 operators was recommended by 2 EMS experts from Alberta based on 3 criteria: 1) maximizing the percentage of the population of Alberta represented by the EMS operators surveyed, 2) adequately reflecting the rural/urban mix of the population and 3) providing a reasonable number of EMS operators to survey.

We surveyed senior personnel at each EMS operator or the base hospital (in the latter case, the respondent answered for all the ambulance operators for whom they were responsible). Surveys were sent via email or, when requested, by regular mail. The study questionnaire was designed to obtain information regarding the following: 1) the availability of 12-lead ECG equipment in ambulances, 2) the training of paramedics in 12-lead ECG acquisition, interpretation and transmission, 3) protocols for expedited transfer of STEMI patients to hospitals with PCI capability from those without PCI, 4) protocols for prehospital bypass of a non-PCI hospital and direct transport to a PCI hospital when EMS personnel suspect STEMI and 5) administration of fibrinolytics by EMS personnel.

We ensured face validity of the survey by focusing the questions on current recommendations with respect to STEMI strategies, ECG equipment and transport protocols. ${ }^{7}$ Questionnaires were tailored for each province to reflect minor variations in the terminology used to describe different levels of training among paramedics. These 2 categories were defined on the cover page of each survey sent. The term "paramedic" in this article is used in a general sense to refer to ambulance personnel with either basic or advanced life support training. We pilot tested the questionnaire among Ontario EMS operators in 2005, and resurveyed Ontario operators with the final version of the survey instrument. For respondents representing EMS operators at the provincial level, variations may have existed within the province in the implementation of prehospital STEMI strategies due to the constraints of geography, paramedic training, medical oversight or the availability of hospital facilities (e.g., cardiac catheterization laboratories). Additional information was obtained from respondents as needed in such cases. Finally, one of the investigators (S.V.) checked all survey responses for consistency, and sought clarification when necessary. The study was approved by the research ethics board of the Sunnybrook Health Sciences Centre.

\section{Statistical analysis}

Statistical analyses comprised frequencies, percentages and $95 \%$ confidence intervals (CIs). All analyses were conducted using SAS version 9. To estimate the proportion of the population covered by the EMS operators surveyed, we used 2006 census data from Statistics Canada. ${ }^{36}$ We used the census area closest to the EMS coverage area if they were not the same. In such cases, we used a census area that included the municipality covered by an EMS operator, and did not include an adjacent municipality covered by a nonsurveyed EMS operator, to estimate the population covered by that EMS operator.

\section{RESULTS}

A total of 97 ambulance operators, representing 15681 paramedics and serving approximately $97 \%$ of the population of the 5 provinces, were surveyed. Fourteen of the 17 operators in Alberta (87.5\%) responded to the survey. In all other provinces, all land EMS operators responded to the survey $(100 \%)$. The only area for which an adjacent census area had to be substituted for an EMS coverage area was Alberta. The number and type of operators and proportion of the population represented in each province are shown in Table 1. There were multiple EMS operators in Alberta, Ontario and Quebec. British Columbia and Nova Scotia each had a single operator for the entire province.

The availability of 12-lead ECG technology (cardiac monitor software and cables) in ambulances increased rapidly during the last decade. The earliest reported use of the technology by our respondents was in 1997 by a single operator in Alberta. However, by 2007, 66 of 97 operators surveyed (68\%, 95\% CI 59\%-77\%) had 12-lead ECG equipment in ambulances. Figure 1 shows the percentage of EMS operators reporting current 12-lead ECG capability in each province. The provincial

\begin{tabular}{|c|c|c|c|c|}
\hline Province & $\begin{array}{l}\text { No. of } \\
\text { operators }\end{array}$ & $\begin{array}{l}\text { No. of } \\
\text { paramedics }\end{array}$ & $\begin{array}{l}\text { Population } \\
\text { covered, \%* }\end{array}$ & $\begin{array}{c}\text { EMS } \\
\text { organization }\end{array}$ \\
\hline $\begin{array}{l}\text { British } \\
\text { Columbia }\end{array}$ & 1 & 2409 & 100.0 & Provincial \\
\hline Alberta & 14 & 1684 & 72.0 & Municipal \\
\hline Ontario & 66 & 7068 & 100.0 & Municipal \\
\hline Quebec & 15 & 3765 & 99.5 & Regional \\
\hline Nova Scotia & 1 & 755 & 100.0 & Provincial \\
\hline Total & 97 & 15681 & 96.6 & \\
\hline
\end{tabular}


EMS organization in Nova Scotia had 12-lead ECG capability across the entire province, and in British Columbia it was limited to 7 urban areas.

Overall, $47 \%$ (95\% CI 46\%-48\%) of paramedics were trained in ECG acquisition, ranging from $9 \%$ (95\% CI $8 \%-10 \%$ ) in British Columbia to $100 \%$ in Nova Scotia (Fig. 2). Across the 5 provinces, $40 \%$ (95\% CI $39 \%-41 \%$ ) of paramedics had training in either direct or automatic ECG interpretation; in Ontario, two-thirds of these paramedics were trained in computergenerated interpretation, whereas the other provinces were more likely to train paramedics in direct tracing interpretation. In Quebec, a small number $(<20)$ of advanced care paramedics exists in 1 urban region. Primary care paramedics (i.e., those who have not been trained to interpret ECGs) serve in the rest of the

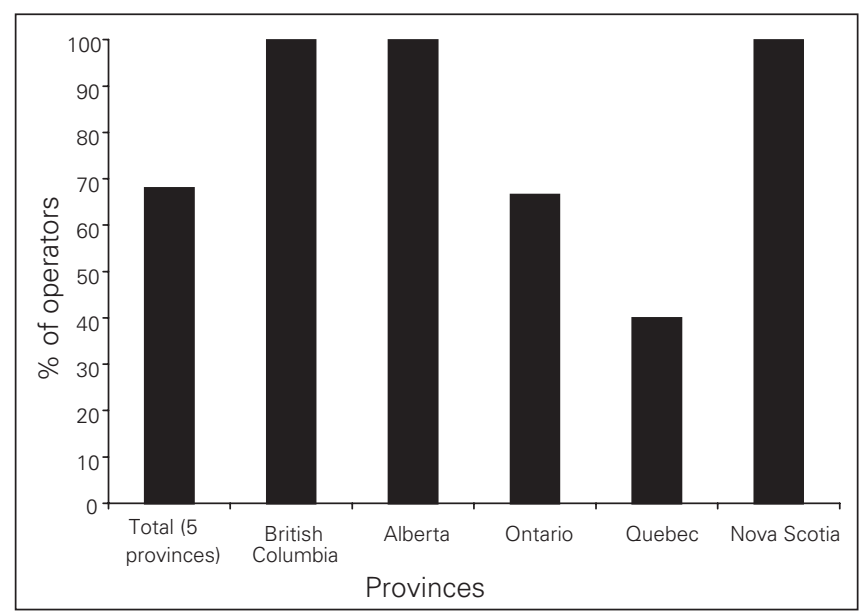

Fig. 1. Prehospital 12-lead electrocardiogram capability (cardiac monitor software and cables), 5 Canadian provinces, 2007.

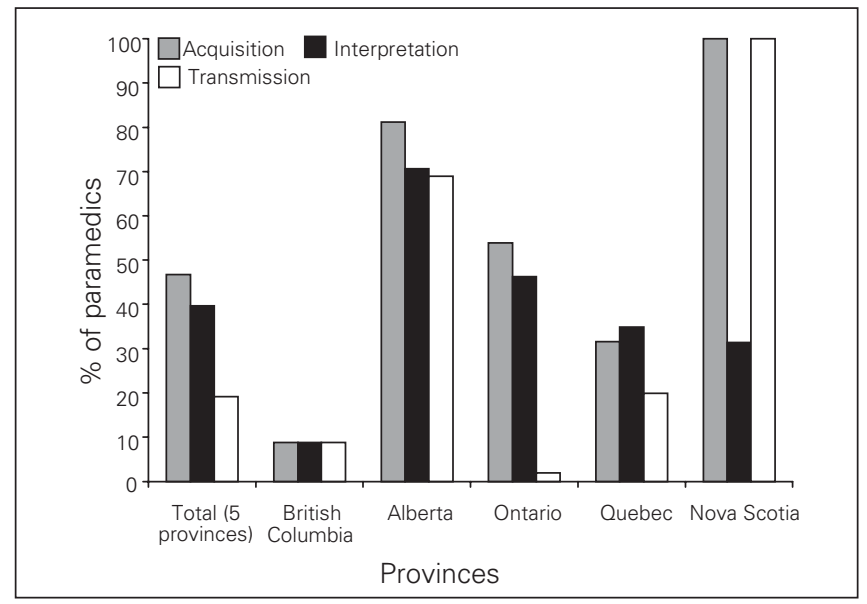

Fig. 2. Primary care and advanced care paramedics trained in the acquisition, interpretation (direct or automatic) and transmission of 12-lead electrocardiograms, 5 Canadian provinces, 2007. province. Only $19 \%$ of paramedics (95\% CI 19\%-20\%) routinely transmitted 12-lead ECGs to the receiving hospital before arrival in cases of suspected STEMI (Fig. 2), although this practice varied widely across provinces.

Expedited transfer from the referring ED to a PCI hospital was available in all provinces except Nova Scotia, with $45 \%$ (44/97, $95 \%$ CI $35 \%-55 \%)$ of operators overall using it "almost always." Although British Columbia's single operator reported the use of expedited transfer protocols and prehospital bypass, their availability was limited to the Victoria area. Protocols for prehospital bypass of a non-PCI hospital for a PCI hospital existed among 7 (50\%, 95\% CI 24\%-76\%) of Alberta's respondents but remained rare among operators in Ontario, Quebec and Nova Scotia (Fig. 3). Prehospital fibrinolysis protocols were used in Alberta by 7 operators (50\% of respondents, $95 \%$ CI $24 \%-76 \%$ ), but were not reported in any other province outside of participation in clinical trials.

Among all 5 provinces, 71 (73\%, 95\% CI 64\%-82\%) EMS operators provided 1 or more of the 4 previously described strategies for more timely access to reperfusion, ranging from $67 \%(10 / 15,95 \%$ CI $43 \%-91 \%)$ of operators in Quebec and 68\% (45/66, 95\% CI 57\%-79\%) in Ontario to $100 \%$ in British Columbia (1 operator), Alberta (14 operators) and Nova Scotia (1 operator). Overall, all EMS operators in Alberta, Nova Scotia and British Columbia used at least 1 strategy (although in British Columbia, availability of some strategies was limited to specific geographic regions), and in Ontario and Quebec, one-third of operators used none of the 4 strategies.

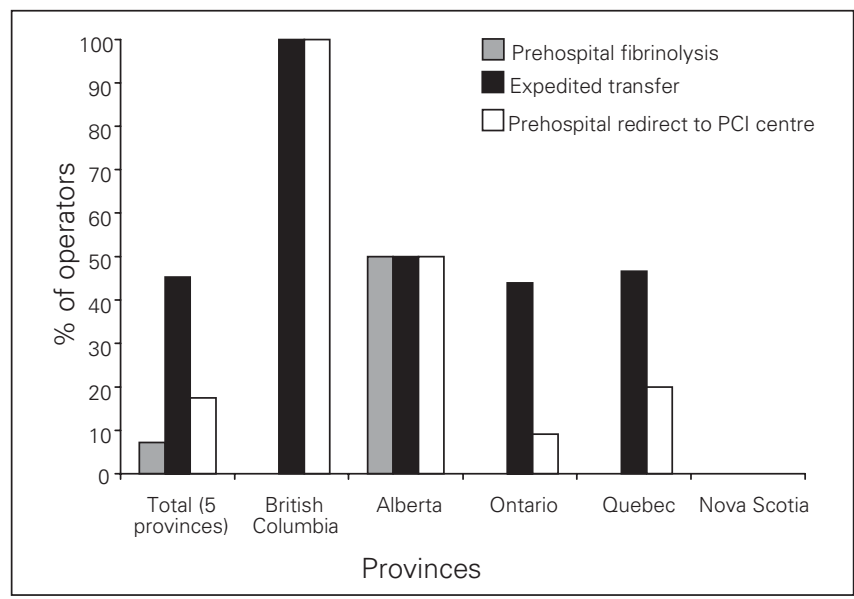

Fig. 3. Prehospital fibrinolysis, expedited transfer to percutaneous coronary intervention $(\mathrm{PCl})$ centre, or prehospital bypass to percutaneous coronary intervention centre, 5 Canadian provinces, 2007. 
When we examined major urban centres within participating provinces, we found that although all centres offered at least 1 of the 3 prehospital strategies 12-lead ECG acquisition, expedited transfer or prehospital bypass, there was considerable variation both within and across provinces with respect to the availability of these services (Table 2).

\section{DISCUSSION}

In this survey of EMS operators in 5 provinces including major urban centres, we found the implementation of prehospital strategies to reduce time to reperfusion for STEMI patients to be highly variable. Overall, less than half of the paramedics were trained in 12-lead ECG acquisition. British Columbia and Quebec lagged behind in paramedic training for 12-lead ECG acquisition, interpretation and transmission, and only 1 operator in Ontario routinely transmitted 12-lead ECGs. The development of prehospital reperfusion protocols for STEMI patients has clearly been uneven across Canada. Prehospital fibrinolysis exists only in Alberta, where half of respondents reported providing the intervention. Prehospital bypass to a PCI hospital has been implemented to some degree in most provinces, but by less than 1 in 5 operators. The underuse of these proven strategies makes it likely that many Canadian STEMI patients who are transported by EMS do not receive timely reperfusion therapy and suffer excess morbidity and mortality accordingly.

Despite a growing body of evidence on the key role of EMS in the prehospital management of STEMI patients, we were unable to identify information showing

\begin{tabular}{|c|c|c|c|}
\hline City & Acquisition & Transfer & Bypass \\
\hline Victoria, BC & Yes & Yes & Yes \\
\hline Vancouver, BC & Yes & No & No \\
\hline Edmonton, $A B$ & Yes & Yes & Yes \\
\hline Calgary, AB & Yes & Yes & Yes \\
\hline Toronto, ON & No & Yes & No \\
\hline Kingston, ON & Yes & Yes & Yes \\
\hline Ottawa, ON & Yes & Yes & Yes \\
\hline Montréal, OC & Yes & No & No \\
\hline Québec, QC & No & Yes & No \\
\hline Halifax, NS & Yes & No & No \\
\hline
\end{tabular}

how this is being translated into practice in North America. A biennial 200-city survey in the Journal of Emergency Medical Services ${ }^{37}$ provided information on EMS capability in the 200 most populated US cities. In its 2007 iteration, $92 \%$ of EMS operators who responded reported having 12-lead ECG equipment in their ambulances; however, the $22 \%$ response rate calls the validity of this finding into question. To our knowledge, there have been no other population-based surveys of EMS operators in North America.

The prehospital strategies we studied were selected based on evidence demonstrating their effectiveness in improving the management and outcomes of STEMI patients, and current practice guidelines and recommendations for their use. Prehospital 12-lead ECGs with advance hospital notification has been shown to be feasible and associated with a reduction in mean time from hospital arrival to fibrinolysis of 11 minutes (from 25 to $36 \mathrm{~min}) .^{15,17,18}$ The AHA/ACC 2007 revision of their 2004 guidelines for STEMI care re-emphasized the need to increase access to prehospital 12-lead ECGs. ${ }^{7,38}$ Other recent studies of prehospital alert (with early activation of the catheterization laboratory), expedited transfer and prehospital bypass demonstrate reductions in time to primary $\mathrm{PCI}^{24,39-49}$ and improved patient outcomes. ${ }^{44}$

Our study indicates that the implementation of these EMS strategies is variable across the 5-province study area, which represents more than $85 \%$ of the Canadian population. Most regions in Canada do not have an optimal prehospital system for STEMI patients, and close integration of prehospital and in-hospital STEMI care is the exception, rather than the norm. Less than half of the more than 15000 paramedics represented by the EMS operators we surveyed were trained in ECG acquisition, which is the first step in building a better prehospital system for STEMI care. Among major Canadian urban centres, all with access to sophisticated in-hospital care for acute myocardial infarction patients, there is wide variability in the availability of prehospital STEMI strategies. For example, Québec and Toronto EMS operators reported none of their ambulances were equipped with 12-lead ECGs, the most widely recommended strategy; and none of Canada's 3 most populated urban centres (i.e., Toronto, Montréal and Vancouver) had protocols for routine prehospital bypass to a PCI hospital during the study period. Finally, only 7 of 97 EMS operators surveyed, all of whom are in Alberta, had adopted fibrinolysis as a prehospital reperfusion strategy. 
The gap between evidence and prehospital practice may be even greater than that identified by this survey. We gathered data on equipment and paramedic training, but the important question of how these translate into actual and appropriate use is unknown. On the other hand, our study was cross-sectional, and thus captures practice at a point in time in a rapidly evolving field, (e.g., several jurisdictions have recently announced plans to implement, or have recently implemented, prehospital ECGs).

Our study was limited to land EMS services and excluded air EMS operators for better interprovincial comparability. Administrative structures of EMS vary markedly across provinces as shown in Table 1. Responses at the provincial level for provincial EMS operators may not fully reflect the variation that exists within a province. In Ontario, the base hospital system has one hospital designated to monitor and ensure the quality of land ambulance prehospital care. In these circumstances, we surveyed senior personnel at the level of the base hospital, who answered for several operators working in the region covered. This may at times have resulted in inaccurate reporting. The highly decentralized EMS administration structure in Alberta made it impractical to survey all of the more than 100 EMS operators in the province; and, given that our unit of analysis was EMS operators, doing so would have resulted in an overrepresentation of small and rural EMS operators. Finally, our 5-province convenience sample was selected for reasons of feasibility and demographic representation, but it is unclear how our findings can be generalized to other regions.

Although our study identified major gaps between recommended prehospital care for STEMI patients and current practice in many parts of Canada, an important unanswered question is who should be accountable for resolving this situation. Emergency medical services are publicly funded and are centrally or regionally coordinated in most Canadian provinces. These are factors that, in theory, offer advantages to the early and widespread adoption of evidence-based technology and protocols. Despite accumulating evidence of benefits associated with prehospital strategies to improve STEMI care, ${ }^{11,20,22,25,32}$ including improved patient outcomes, ${ }^{44}$ our results suggest that many EMS operators have yet to implement such strategies. However, the technologies, policies and protocols we examined require substantial investment in equipment and training, more sophisticated real-time communications and medical control, and negotiations and formal agreements between EMS providers, hospital-based providers (e.g., emergency physicians, interventional cardiologists) and health authorities (e.g., provincial or regional), who may have limited experience in working closely with one another. It is only with a concerted and sustained effort by the key stakeholders that such changes are likely to occur, and it is hoped that the novel comparative data in this publication will serve as a stimulus for health regions across Canada to improve their EMS so that STEMI care may be optimized for more patients.

Since advanced cardiac care is highly regionalized in Canada ${ }^{50}$ one important step toward more integrated STEMI care for more Canadians, from the 911 call to the initiation of reperfusion therapy, would be for more health authorities to identify the problem as a regional priority, thus bringing all stakeholders together, providing a framework for cooperation, ensuring adequate funding is present and monitoring outcomes. Both Ottawa and Calgary have established such models over periods of several years, ${ }^{20,22}$ but our results show there are many other Canadian regions that lag significantly behind. The implementation of high-quality care for acute conditions, such as STEMI and stroke, requires the seamless integration of medical care provided in prehospital, acute hospital and postacute settings, and regional health authorities are in the best position to assume responsibility and leadership for facilitating this, ensuring more widespread adoption of complex strategies of this nature across health system domains. Wider adoption of prehospital strategies and closer integration with hospital-based care is likely to reduce time to reperfusion and significantly improve outcomes for STEMI patients throughout Canada.

\section{CONCLUSION}

The implementation of widely recommended prehospital STEMI strategies varies substantially across the 5 provinces studied, and relatively simple existing technologies, such as prehospital ECGs are underused in many regions. Substantial improvements in prehospital services and better integration with hospital-based care will be necessary in many regions of Canada if optimal times to reperfusion, and associated outcomes, are to be achieved.

Acknowledgements: The authors thank Dr. Hal Canham and Dr. Daniel Lefrançois for their assistance in completing this study. The study was supported by a Canadian Institutes for Health Research Team Grant in Cardiovascular Outcomes Research and a grant from the Heart and Stroke Foundation of Ontario. Dr. Schull is supported by an Applied Chair in Health 
Services and Policy Research, Canadian Institutes of Health Research, and Dr. Tu is supported by a Canada Research Chair in Health Services Research and a Career Investigator Award from the Heart and Stroke Foundation of Ontario.

Competing interests: None declared.

\section{REFERENCES}

1. Nallamothu BK, Bates ER, Herrin J, et al. Times to treatment in transfer patients undergoing primary percutaneous coronary intervention in the United States: National Registry of Myocardial Infarction (NRMI)-3/4 analysis. Circulation 2005;111:761-7.

2. Boersma E, Maas AC, Deckers JW, et al. Early thrombolytic treatment in acute myocardial infarction: reappraisal of the golden hour. Lancet 1996;348:771-5.

3. De Luca G, Ernst N, Suryapranata H, et al. Relation of interhospital delay and mortality in patients with ST-segment elevation myocardial infarction transferred for primary coronary angioplasty. Am J Cardiol 2005;95:1361-3.

4. McLellan CS, Le May MR, Labinaz M. Current reperfusion strategies for ST elevation myocardial infarction: a Canadian perspective. Can J Cardiol 2004;20:525-33.

5. Steg PG, Bonnefoy E, Chaubaud S, et al. Impact of time to treatment on mortality after prehospital fibrinolysis or primary angioplasty: data from the CAPTIM randomized clinical trial. Circulation 2003;108:2851-6.

6. Nallamothu BK, Bates ER. Percutaneous coronary intervention versus fibrinolytic therapy in acute myocardial infarction: is timing (almost) everything? Am J Cardiol 2003;92:824-6.

7. Antman EM, Hand M, Armstrong PW, et al. 2007 Focused update of the ACC/AHA 2004 guidelines for the management of patients with ST-elevation myocardial infarction. A report of the American College of Cardiology/American Heart Association Task Force on Practice Guidelines. Circulation 2008;117:296-329.

8. Nallamothu BK, Bradley EH, Krumholz HM. Time to treatment in primary percutaneous coronary intervention. $N$ Engl 7 Med 2007;357:1631-8.

9. Eagle KA, Goodman SG, Avezum A, et al. Practice variation and missed opportunities for reperfusion in ST-segmentelevation myocardial infarction: findings from the Global Registry of Acute Coronary Events (GRACE). Lancet 2002; 359:373-7.

10. Tu JV. Quality of cardiac care in Ontario. Toronto (ON): Institute for Clinical Evaluative Sciences; 2005.

11. Welsh RC, Ornato J, Armstrong PW. Prehospital management of acute ST-elevation myocardial infarction: a time for reappraisal in North America. Am Heart J 2003;145:1-8.

12. The Macstrack Project Office. ACO - understanding time to treatment. Macstrak Quarterly 2004;11:1-2.
13. The Macstrack Project Office. Practice guidelines - acute coronary occlusion (ACO). Macstrak Quarterly 2005;12:1-2.

14. The Macstrack Project Office. Reperfusion therapy time reports updated. Macstrak Quarterly 2007;14:1-2.

15. Brainard AH, Raynovich $W$, Tandberg D, et al. The prehospital 12-lead electrocardiogram's effect on time of initiation of reperfusion therapy: a systematic review and meta-analysis of existing literature. Am J Emerg Med 2005;23:351-6.

16. Garvey JL, MacLeod BA, Sopko G, et al. Pre-hospital 12-lead electrocardiography programs: a call for implementation by emergency medical services systems providing advanced life support - National Heart Attack Alert Program (NHAAP) Coordinating Committee; National Heart, Lung, and Blood Institute (NHLBI); National Institutes of Health. 7 Am Coll Cardiol 2006;47:485-91.

17. Morrison LJ, Brooks S, Sawadsky B, et al. Prehospital 12-lead electrocardiography impact on acute myocardial infarction treatment times and mortality: a systematic review. Acad Emerg Med 2006;13:84-9.

18. Adams GL, Campbell PT, Adams JL. Effectiveness of prehospital wireless transmission of electrocardiograms to a cardiologist via hand-held device for patients with acute myocardial infarction. Am J Cardiol 2006;98:1160-4.

19. American Heart Association. D2B: an alliance for quality. Available: www.d2balliance.org (accessed 2009 Jul 28).

20. de Villiers JS, Anderson T, McMeekin JD, et al. Expedited transfer for primary percutaneous coronary intervention: a program evaluation. CMAJ 2007;176:1833-8.

21. Jollis JG, Roettig ML, Aluko AO, et al. Implementation of a statewide system for coronary reperfusion for ST-segment elevation myocardial infarction. JAMA 2007;298:2371-80.

22. Le May MR, Davies RF, Dionne R, et al. Comparison of early mortality of paramedic-diagnosed ST-segment eleveation myocardial infarction with immediate transport to a designated primary percutaneous coronary intervention center to that of similar patients transported to the nearest hospital. Am 7 Cardiol 2006;98:1329-33.

23. Ortolani P, Marzocchi A, Marrozzini C, et al. Clinical impact of direct referral to primary percutaneous coronary intervention following pre-hospital diagnosis of ST-elevation myocardial infarction. Eur Heart 7 2006;27:1550-7.

24. Dorsch MF, Greenwood JP, Priestley C. Direct ambulance admission to the cardiac catheterization laboratory significantly reduces door-to-balloon times in primary percutaneous coronary intervention. Am Heart 7 2008;155:1054-8.

25. Armstrong PW. A comparison of pharmacological therapy with/without timely coronary intervention vs. primary percutaneous intervention early after ST-elevation myocardial infarction: the WEST (Which Early ST-elevation myocardial infarction Therapy) study. Eur Heart 7 2006;27:1530-8.

26. Bjorklund E, Stenestrand U, Lindback J, et al. Pre-hospital thrombolysis delivered by paramedics is associated with 
reduced time delay and mortality in ambulance-transported real-life patients with ST-elevation myocardial infarction. Eur Heart J 2006;27:1146-52.

27. Bonnefoy E, Lapostolle F, Leizorovicz A, et al. Primary angioplasty versus prehospital fibrinolysis in acute myocardial infarction: a randomised study. Lancet 2002;360:825-9.

28. Danchin N, Blanchard D, Steg PG, et al. Impact of prehospital thrombolysis for acute myocardial infarction on 1-year outcome: results from the French Nationwide USIC 2000 Registry. Circulation 2004;110:1909-15.

29. Lamfers EJ, Schut A, Hertzberger DP, et al. Prehospital versus hospital fibrinolytic therapy using automated versus cardiologist electrocardiographic diagnosis of myocardial infarction: abortion of myocardial infarction and unjustified fibrinolytic therapy. Am Heart J 2004;147:509-15.

30. Morrison LJ, Verbeek PR, McDonald AC, et al. Mortality and prehospital thrombolysis for acute myocardial infarction: a meta-analysis. JAMA 2000;283:2686-92.

31. Morrow DA, Antman EM, Sayah A, et al. Evaluation of the time saved by prehosptial initiation of reteplase for ST-elevation myocardial infarction: results of The Early Retavase-Thrombolysis in Myocardial Infarction (ER-TIMI) 19 trial. 7 Am Coll Cardiol 2002;40:71-7.

32. Welsh RC, Travers A, Senaratne M, et al. Feasibility and applicability of paramedic-based prehospital fibrinolysis in a large North American center. Am Heart 7 2006;152:1007-14.

33. Armstrong PW, Bogaty P, Buller CE, et al. The 2004 ACC/AHA Guidelines: a perspective and adaptation for Canada by the Canadian Cardiovascular Society Working Group. Can 7 Cardiol 2004;20:1075-9.

34. Moyer P, Ornato JP, Brady WJ Jr, et al. Development of systems of care for ST-elevation myocardial infarction patients: the emergency medical services and emergency department perspective. Circulation 2007;116:e43-8.

35. Canto JG, Rogers WJ, Bowlby LJ, et al. The prehospital electrocardiogram in acute myocardial infarction: is its full potential being realized? National Registry of Myocardial Infarction 2 Investigators. 7 Am Coll Cardiol 1997;29:498-505.

36. Census 2006. Ottawa (ON): Statistics Canada; 2006. Available: www12.statcan.gc.ca/census-recensement/2006/geo /index-eng.cfm (accessed 2009 Jul 24).

37. Williams DM. 200 city survey: Is the status quo acceptable? JEMS 2008;33:48-65.

38. Antman EM, Anbe DT, Armstrong PW, et al. ACC/AHA guidelines for the management of patients with ST-elevation myocardial infarction; A report of the American College of Cardiology/American Heart Association Task Force on Practice Guidelines (Committee to Revise the 1999 Guidelines for the Management of patients with acute myocardial infarction). 7 Am Coll Cardiol 2004;44:E1-211.

39. Adams GL, Campbell PT, Adams JM, et al. Effectiveness of prehospital wireless transmission of electrocardiograms to a cardiologist via hand-held device for patients with acute myocardial infarction (from the Timely Intervention in Myocardial Emergency, NorthEast Experience [TIMENE]). Am J Cardiol 2006;98:1160-4.

40. Bradley EH, Herrin J, Wang Y, et al. Strategies for reducing the door-to-balloon time in acute myocardial infarction. N Engl J Med 2006;355:2308-20.

41. Clemmensen P, Sejersten M, Sillesen M, et al. Diversion of ST-elevation myocardial infarction patients for primary angioplasty based on wireless prehospital 12-lead electrocardiographic transmission directly to the cardiologist's handheld computer. J Electrocardiol 2005;38:194-8.

42. Drew BJ, Dempsey ED, Joo TH, et al. Pre-hospital synthesized 12-lead ECG ischemia monitoring with trans-telephonic transmission in acute coronary syndromes: pilot study results of the ST SMART trial. J Electrocardiol 2004;37:214-21.

43. Gross BW, Dauterman KW, Moran MG, et al. An approach to shorten time to infarct patency in patients with ST-segment elevation myocardial infarction. Am J Cardiol 2007;99:1360-3.

44. Le May MR, So DY, Dionne R, et al. A citywide protocol for primary PCI in ST-segment elevation myocardial infarction. N Engl J Med 2008;358:231-40.

45. Sekulic M, Hassunizadeh B, McGraw S, et al. Feasibility of early emergency room notification to improve door-toballoon times for patients with acute ST segment elevation myocardial infarction. Catheter Cardiovasc Interv 2005;66: $316-9$.

46. Strauss DG, Sprague PQ, Underhill K, et al. Paramedic transtelephonic communication to cardiologist of clinical and electrocardiographic assessment for rapid reperfusion of ST-elevation myocardial infarction. J Electrocardiol 2007;40: $265-70$

47. Swor R, Hegerberg S, McHugh-McNally A, et al. Prehospital 12-lead ECG: Efficacy or effectiveness? Prehosp Emerg Care 2006;10:374-7.

48. Terkelsen CJ, Lassen JF, Norgaard BL, et al. Reduction in treatment delay in patients with ST-elevation myocardial infarction: Impact of pre-hospital diagnosis and direct referral to primary percutaneous coronary intervention. Eur Heart 72005;26:770-7.

49. van't Hof AW, Rasoul S, van de Wetering $H$, et al. Feasibility and benefit of prehospital diagnosis, triage, and therapy by paramedics only in patients who are candidates for primary angioplasty for acute myocardial infarction. Am Heart 7 2006;151:1255 e1-5.

50. Alter DA, Stukel TA, Newman A. The relationship between physician supply, cardiovascular health service use and cardiac disease burden in Ontario: supply-need mismatch. Can J Cardiol 2008;24:187-93.

Correspondence to: Dr. Michael Schull, G-106, Institute for Clinical Evaluative Sciences, 2075 Bayview Ave., Toronto ON M4N 3M5; mjs@ices.on.ca 